\title{
Difficult airway and difficult intubation in postintubation tracheal stenosis: a case report and literature review
}

This article was published in the following Dove Press journal:

Therapeutics and Clinical Risk Management

18 June 2012

Number of times this article has been viewed

\author{
Paul Zarogoulidis' \\ Theodoros Kontakiotis' \\ Kosmas Tsakiridis ${ }^{2}$ \\ Michael Karanikas ${ }^{3}$ \\ Christos Simoglou ${ }^{4}$ \\ Konstantinos Porpodis' \\ Alexandros Mitrakas ${ }^{3}$ \\ Agisilaos Esebidis ${ }^{3}$ \\ Maria Konoglou ${ }^{5}$ \\ Nikolaos Katsikogiannis ${ }^{6}$ \\ Vasilis Zervas' \\ Christina Aggelopoulou ${ }^{7}$ \\ Dimitrios Mikroulis ${ }^{4}$ \\ Konstantinos Zarogoulidis' \\ 'Pulmonary Department, \\ "G Papanikolaou" General Hospital, \\ Aristotle University of Thessaloniki, \\ Thessaloniki, Greece; ${ }^{2}$ Cardiothoracic \\ Department, Saint Luke Private \\ Hospital, Thessaloniki, Greece; \\ ${ }^{3}$ Ist University Surgery Department, \\ ${ }^{4}$ Cardiothoracic Department, \\ University General Hospital of \\ Alexandroupolis, Democritus \\ University of Thrace, Alexandroupolis, \\ Greece; ${ }^{5}$ Ist Pulmonary Department, \\ "G Papanikolaou" General Hospital, \\ Aristotle University of Thessaloniki, \\ Thessaloniki, Greece; ' ${ }^{6}$ urgery \\ Department (NHS), ${ }^{7}$ Neurology \\ Department (NHS), University \\ General Hospital of Alexandroupolis, \\ Democritus University of Thrace, \\ Alexandroupolis, Greece
}

Correspondence: Paul Zarogoulidis

Pulmonary Department,

"G Papanikolaou" General Hospital,

Aristotle University of Thessaloniki,

Thessaloniki, Greece

Tel +30 697727 I974

Fax +30 23। 0992433

Email pzarog@hotmail.com

\begin{abstract}
Management of a "difficult airway" remains one of the most relevant and challenging tasks for anesthesiologists and pulmonary physicians. Several conditions, such as inflammation, trauma, tumor, and immunologic and metabolic diseases, are considered responsible for the difficult intubation of a critically ill patient. In this case report we present the case of a 46-year-old male with postintubation tracheal stenosis. We will focus on the method of intubation used, since the patient had a "difficult airway" and had to be intubated immediately because he was in a life-threatening situation. Although technology is of utter importance, clinical examination and history-taking remain invaluable for the appropriate evaluation of the critically ill patient in everyday medical life. Every physician who will be required to perform intubation has to be familiar with the evaluation of the difficult airway and, in the event of the unanticipated difficult airway, to be able to use a wide variety of tools and techniques to avoid complications and fatality.
\end{abstract}

Keywords: difficult airway, bronchoscopic intubation, predictive factors, predictive scales

\section{Introduction}

Failed or difficult endotracheal intubation is a significant cause of morbidity and mortality during anesthesia. ${ }^{1}$ It has been estimated that inability to successfully manage a difficult airway has been responsible for as many as $30 \%$ of deaths attributable to anesthesia. Waiting too long before manipulation of the airway could increase the partial pressure of the volatile anesthetic in the body and result in apnea and bradycardia. The reported incidence of difficult intubation is one in every 65 patients. Fiberoptic bronchoscopes and laryngeal mask airways have contributed to a large extent to the management of difficult airway. ${ }^{2}$ Several methods have been introduced to identify patients who are in danger of difficult intubation before the initiation of anesthesia. . $^{3,4}$ Not all cases can be identified before anesthesia, however, and many cases of difficult intubation arise after trying to find the vocal cords by direct laryngoscopy once unconsciousness has been induced and the skeletal muscles relaxed. The actual difficulties surrounding intubation can only be determined by grading the exposure of the vocal cords by conventional direct laryngoscopy. ${ }^{5}$

A number of devices are available to manage the difficult airway, including flexible fiberoptic bronchoscopes, the rigid optical stylet, light wands, rigid fiberscopes, the Bullard ${ }^{\mathrm{TM}}$ laryngoscope, (BL, Gyrus ACMI, Southborough, MA), the Augustine Scope, (Augustine Biomedical + Design, Eden Prarie, MN), the intubation laryngeal mask airway, and the visualized endotracheal tube. ${ }^{6}$ Flexible fiberoptic bronchoscopy is immensely useful for the critical-care doctor in the management of difficult 
tracheal intubations (DTIs), evaluation of the upper airway, verification of endotracheal tube placement, repositioning or checking of patency of endotracheal tubes, changing of endotracheal tubes, placement of double lumen tubes, and placement of endobronchial blockers. The flexible fiberoptic intubation bronchoscope gives the competent practitioner the unparalleled opportunity to secure almost any difficult airway encountered. ${ }^{7}$ The flexible fiberoptic bronchoscope is regarded as the gold standard in planning predicted difficult airway management, but numerous hours of training are necessary to optimize control of this device. ${ }^{8-10}$

\section{Case report}

A 46-year-old man was admitted to the emergency department with exertional dyspnea, wheezing, and respiratory acidosis. Three days earlier he had been discharged from a tertiary hospital after being hospitalized for 15 days due to a labor accident. He had sustained bilateral pneumothorax, hemithorax, and rib fractures. Upon his admission at that time he was intubated for 5 (out of 15) days. He was discharged in a generally good condition. The patient was a lifetime nonsmoker and he was not receiving any medications. Nevertheless, he had morbid obesity, with a body mass index of $>45$.

On admission the patient had tachypnea (respiratory rate 35 breaths/minute), inspiratory stridor, and tachycardia (heart rate 135 beats per minute); use of accessory respiratory muscles was noticed and he was unconscious, responding only to painful stimuli. His arterial blood gas revealed respiratory acidosis: partial pressure of oxygen $48 \mathrm{mmHg}$, partial pressure of carbon dioxide $75 \mathrm{mmHg}, \mathrm{pH} \mathrm{6.80,} \mathrm{and} \mathrm{bicarbonate}$ $43 \mathrm{mmol} / \mathrm{L}$, with on-air fraction of inspired oxygen of $21 \%$. A chest X-ray revealed blunting of the left costophrenic angle and evidence of tracheal stenosis (Figure 1A). Therefore, a computed tomography scan of the thorax was performed and revealed narrowing of the trachea at the level of the thyroid gland (Figure 2B).

Upon discharge the patient was given painkillers and anticoagulant treatment with low-molecular-weight heparin. Systemic corticosteroids (methylprednisolone) and inhaled treatment with nebulizer (bronchodilators ipratropium bromide and budesonide) were administered.

The patient was ventilated with an Ambu face mask (DIGAS GEORGE \& Co., Thessaloniki, Greece) during his transport to the hospital and during the radiologic examination. Noninvasive ventilation was applied with a bilevel positive airway pressure model of inspiratory positive airway pressure of 12 and expiratory positive airway pressure of
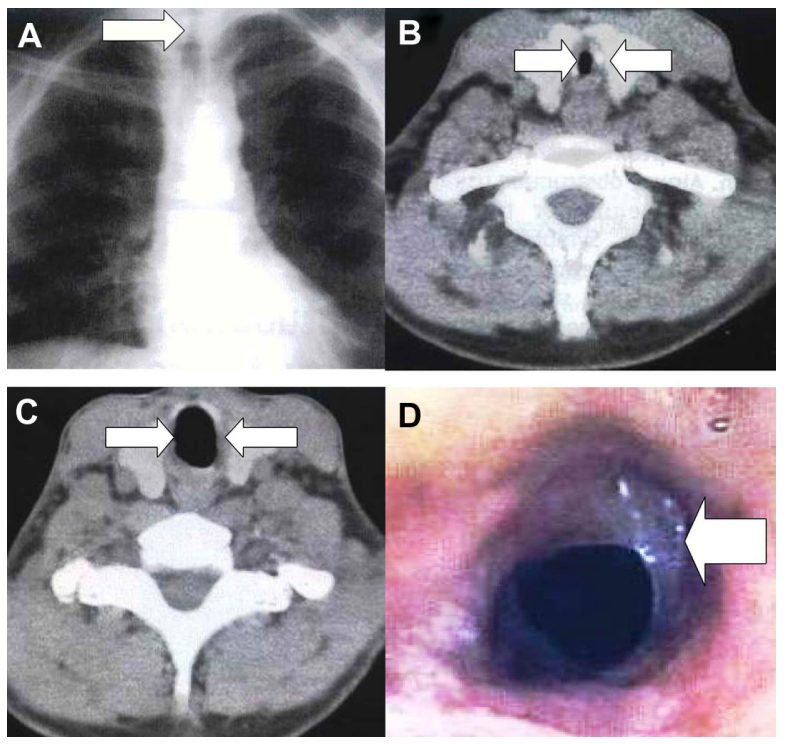

Figure I (A) Chest X-ray upon admission. (B) Computed tomography scan of neck upon admission. (C) Computed tomography scan of neck post-laser intervention and systemic treatment. (D) Bronchoscopic findings demonstrating (web-like) fibrotic stenosis.

6, and titration was applied according to the arterial blood gas, but the patient continued to have respiratory acidosis. Attempting to intubate the patient to sustain ventilation revealed edema of the oropharyngeal structures.

Since all attempts to intubate with lighted stylet failed, we decided to apply a laryngeal supraglottic steel handle mask. The patient was admitted into the intensive care unit and, with the use of a fiberoptic bronchoscope (model 11301ABN1, Storz insertion cord diameter $2.8 \mathrm{~mm}$, insertion cord length $500 \mathrm{~mm}$, working channel $1.2 \mathrm{~mm}$; Karl Storz GmbH \& Co. $\mathrm{KG}$, Tuttlingen, Germany), an endotracheal tube of $7.5 \mathrm{~mm}$ (high-volume, low-pressure; Well Lead Medical Co, Guangzhou, China) was inserted. A red stomach tube (Levin's type) of 18 (Fr/Ch) or $6.7 \mathrm{~mm}$ (size OD; Well Lead Medical Co) was firstly applied throughout the bronchoscope and was inserted into the laryngeal mask to be used as a guide for the endotracheal tube that we intended to use (Figures 2 and 3). The fiberoptic bronchoscope revealed a membranous weblike stenosis of the trachea (Figure 1D). The Levin tube was placed and the fiberoptic bronchoscope was removed. The endotracheal tube was then applied with the Levin tube as a guide. All laboratory findings were normal. The patient was ventilated with an Evita 2 Dura ventilator (Dräger Medical $\mathrm{GmbH}$, Lübeck, Germany) (Figure 4). We attributed the formation of the membranous tissue and consequently the tracheal stenosis to the former intubation period. Endoscopic treatment with laser incision and systematic steroid administration provided the solution (Figure 1C). The arterial blood 


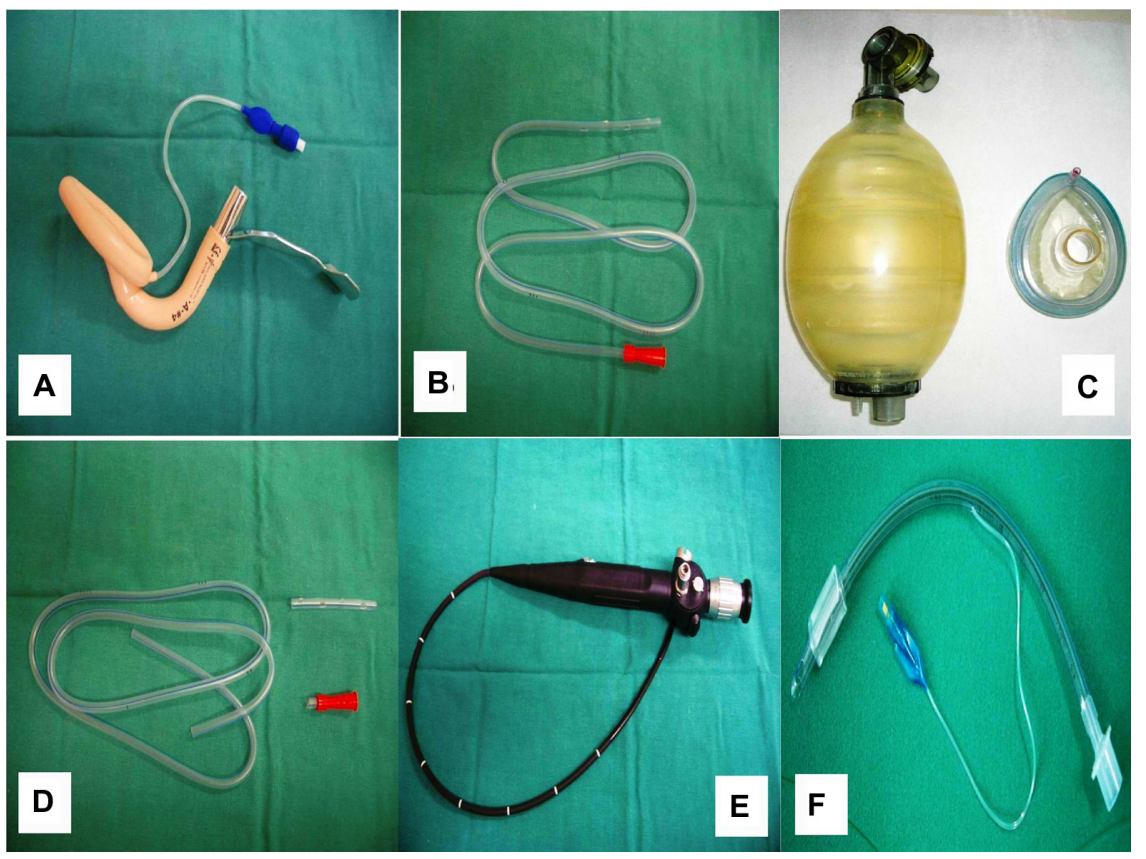

Figure $2(\mathbf{A}-\mathbf{C})$ Application of the Levin tube through the bronchoscope (steps). (D) Demonstration of the laryngeal mask with the bronchoscope and Levin tube. (E) Levin tube within the laryngeal steel handle mask. (F) Endotracheal tube with the Levin tube inserted as a guide.

gas on air after the endoscopic treatment was partial pressure of oxygen $82 \mathrm{mmHg}$, partial pressure of carbon dioxide $37 \mathrm{mmHg}, \mathrm{pH} 7.42$, and bicarbonate $22 \mathrm{mmol} / \mathrm{L}$.

\section{Discussion}

The difficult airway has been defined as "the clinical situation in which a conventionally trained anesthetist experiences difficulty with mask ventilation of the upper airway, tracheal intubation, or both." ${ }^{10}$ DTI accounts for $17 \%$ of respiratoryrelated injuries and results in significant morbidity and mortality. ${ }^{1}$ In fact, up to $28 \%$ of all deaths associated with anesthesia are due to the inability of a mask to ventilate or intubate. ${ }^{1}$ The American Society of Anesthesiologists defines a difficult airway as the existence of clinical factors

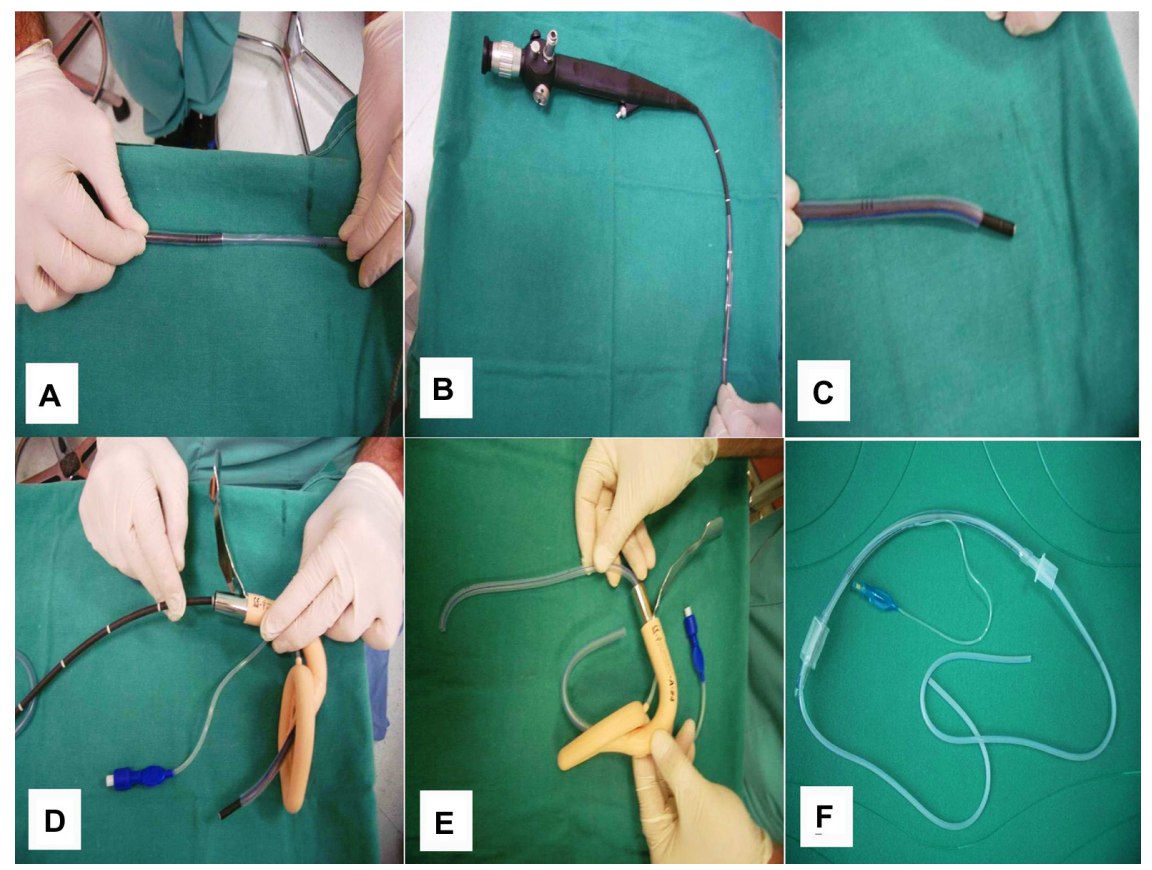

Figure 3 (A) Laryngeal steel handle mask. (B) Levin tube. (C) Ambu face mask. (D) Levin tube with the edges cut off. (E) Bronchoscope. (F) Endotracheal tube. 


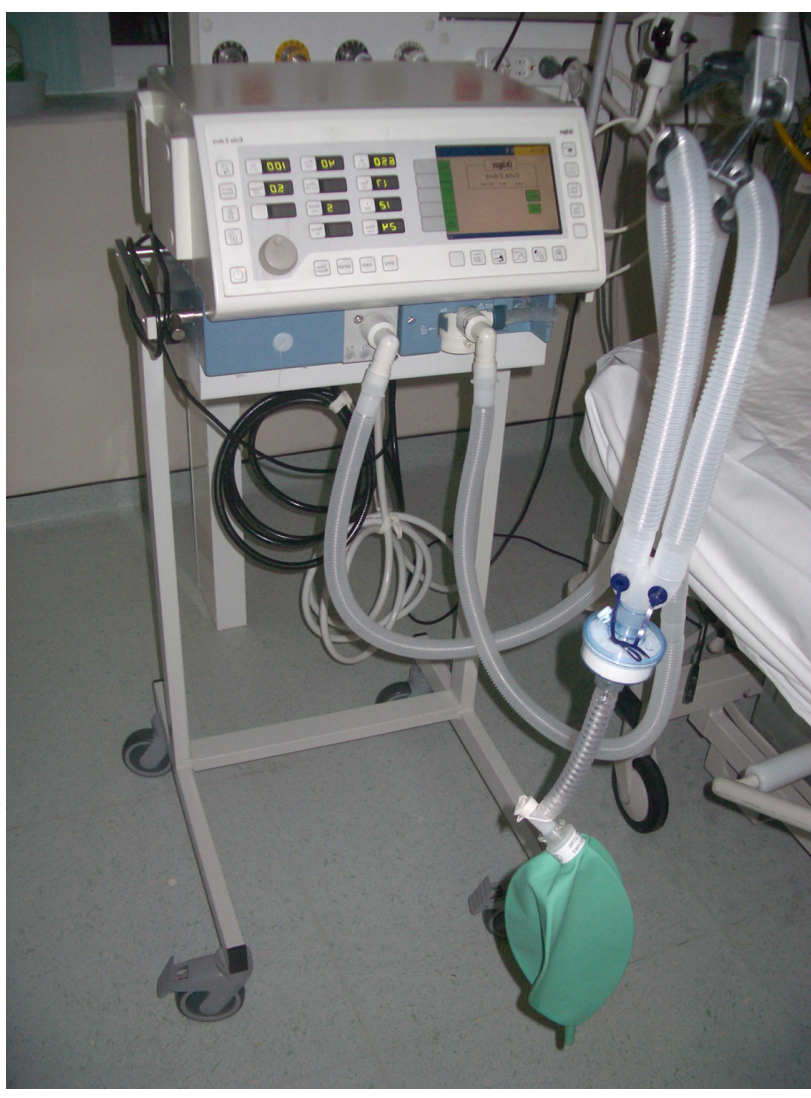

Figure 4 Evita 2 Dura (Dräger, Medical GmbH, Lübeck, Germany).

that complicate both ventilation administered through a face mask and intubation performed by an experienced person. The difficult airway algorithm of the American Society of Anesthesiologists was developed to guide clinicians in the management of the patient who is either predicted to have a difficult airway or whose airway cannot be adequately managed after induction of anesthesia. ${ }^{10}$

Though the American Society of Anesthesiologists' taskforce did not attempt to enumerate the features that identify those patients who may prove difficult to manage, it did recognize that an airway evaluation should be performed. Difficult ventilation is defined as the inability of a trained anesthesiologist to maintain oxygen saturation $>90 \%$ using a face mask, with a goal of oxygen fraction of $100 \%$. Difficult intubation is defined as the need for more than three attempts for intubation of the trachea or more than 10 minutes to achieve it, a situation that occurs in between $1.5 \%$ and $8 \%$ of general anesthesia procedures. ${ }^{11,12}$ Greater degree of difficulty in intubation is associated with greater incidence and severity of complications. ${ }^{13}$

Up to $30 \%$ of anesthetic deaths can be attributed to a compromised airway. ${ }^{14}$ This has generated the need for highly predictive tests for the identification of an airway with assumed intubation difficulty, to be applicable in all anesthetic and surgical procedures. ${ }^{10,15}$

There are several factors that may cause tracheal stenosis, including traumatic conditions, inflammatory diseases, benign and malignant lesions, collagen vascular diseases, and congenital conditions. Of these causes the leading cause of tracheal stenosis still continues to be endotracheal intubation, despite technological improvements such as the introduction of high-volume low-pressure cuffs and better patient care. Local inflammation and ischemia caused by an endotracheal tube can result in the upregulation of the fibrinolytic pathway, including $\mathrm{C}$ and $\mathrm{S}$ proteins locally, resulting in the creation of membranous-like stenosis. ${ }^{16}$ Two studies, the first by Spittle and Beavis ${ }^{16}$ and the second by Spittle and McCluskey, ${ }^{17}$ present data that elucidate the underlying mechanism when a cuff pressure greater than $30 \mathrm{mmHg}$ exceeds a critical point in the mucosal capillary perfusion pressure, causing mucosal ischemia leading to ulceration, chondritis of the tracheal cartilages, and, ultimately, development of irreversible fibrotic tissue. The endotracheal tube cuff causes circumferential erosion of the mucosa, which heals with a concentric (web-like) stenosis. It has been reported that based on the length of tracheal stenosis, the depth of the tracheal wall involvement, and the presence or not of tracheomalacia, postintubation tracheal stenosis falls into three categories: short, "complex", and "pseudoglottic". ${ }^{18}$

Assessment of a difficult airway begins with a comprehensive medical history, and physical and regional examination. There are several key elements for the clinician to check: (1) variations in normal anatomy; (2) pathologic conditions; (3) a small mouth opening; (4) protruding upper teeth; (5) a large tongue; and (6) immobility of the head, neck, and jaw. Variations in "normal" anatomy and characteristic airway anatomy resulting from pathologic conditions can result in problems despite proper positioning and equipment (Tables 1 and 2).

Moreover, several conditions have been reported to predispose patients to difficult airway intubation. These conditions include infections, trauma, obesity, endocrine factors, foreign body, tumors, inflammatory conditions, congenital problems, and physiologic conditions (Table 2).$^{10}$ Difficult airway intubation can result in numerous complications (Table 3). Infections such as epiglottitis, abscesses, croup, bronchitis, and pneumonia can affect airway management. ${ }^{19}$ Radiological methods such as a computed tomography scan or a lateral neck radiograph may be helpful as an initial management of the underlying condition and should 
Table I Most valuable scales/distances used in the prediction of difficult airway

\begin{tabular}{|c|c|c|}
\hline & Technique classification & \\
\hline I. Mallampati scale & $\begin{array}{l}\text { Patient seated with head in complete extension, } \\
\text { carrying out phonation and with the tongue within } \\
\text { the mouth }\end{array}$ & $\begin{array}{l}\text { Class I: visibility of soft palate, uvula, and amygdaline pillars } \\
\text { Class II: visibility of soft palate and uvula } \\
\text { Class III: visibility of soft palate and base of uvula } \\
\text { Class IV: impossibility of visualizing soft palate }\end{array}$ \\
\hline $\begin{array}{l}\text { 2. Patil-Aldreti scale } \\
\text { (thyromental distance) }\end{array}$ & $\begin{array}{l}\text { Patient seated, head extended and mouth closed; } \\
\text { distance that exists between the thyroid cartilage } \\
\text { (upper recess) and the lower border of the chin } \\
\text { is evaluated }\end{array}$ & $\begin{array}{l}\text { Class I: }>6.5 \mathrm{~cm} \text { (endotracheal laryngoscopy and intubation } \\
\text { without difficulty) } \\
\text { Class II: } 6-6.5 \mathrm{~cm} \text { (laryngoscopy and intubation with a certain } \\
\text { level of difficulty) } \\
\text { Class III: }<6 \mathrm{~cm} \text { (very difficult laryngoscopy and intubation) }\end{array}$ \\
\hline 3. Sternomental distance & $\begin{array}{l}\text { Patient seated, head in complete extension and } \\
\text { mouth closed; distance of a straight line going from } \\
\text { the superior border of the manubrium of the } \\
\text { sternum to the point of the chin is evaluated }\end{array}$ & $\begin{array}{l}\text { Class I: }>13 \mathrm{~cm} \\
\text { Class II: } 12-13 \mathrm{~cm} \\
\text { Class III: } 11-12 \mathrm{~cm} \\
\text { Class IV: }<11 \mathrm{~cm}\end{array}$ \\
\hline $\begin{array}{l}\text { 4. Cormack-Lehane } \\
\text { classification }\end{array}$ & $\begin{array}{l}\text { Direct laryngoscopy is carried out; grade } \\
\text { of difficulty achieving endotracheal } \\
\text { intubation according to visualized anatomic } \\
\text { structures is evaluated }\end{array}$ & $\begin{array}{l}\text { Grade I: Glottic ring is observed in total (intubation very easy) } \\
\text { Grade II: commissure or upper half of glottic ring is observed } \\
\text { (difficult) } \\
\text { Grade III: Only epiglottis is observed with visualization of the } \\
\text { glottic opening (very difficult) } \\
\text { Grade IV: impossible to visualize the epiglottis (intubation only } \\
\text { possible with special techniques) }\end{array}$ \\
\hline
\end{tabular}

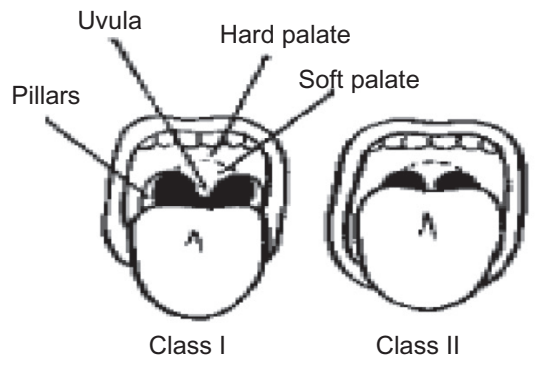

Scale I

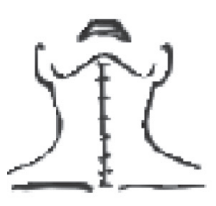

Scale 3

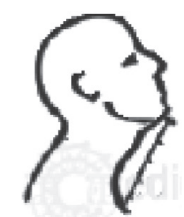

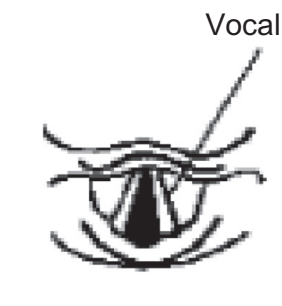

Grade I

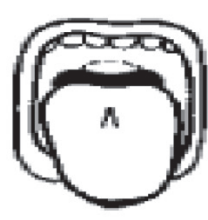

Class III
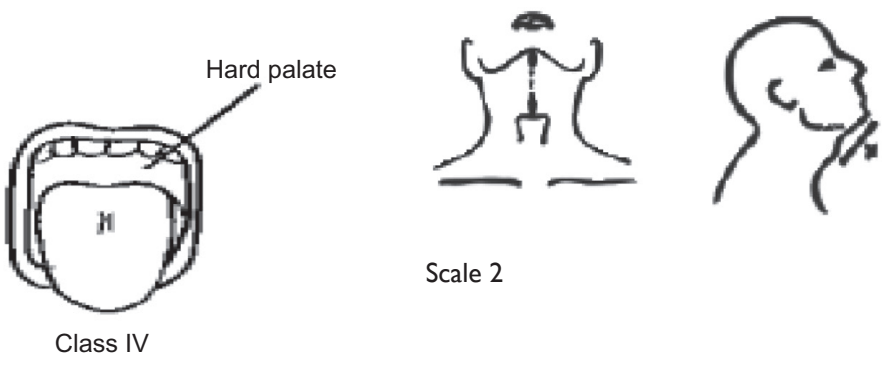

Scale 2

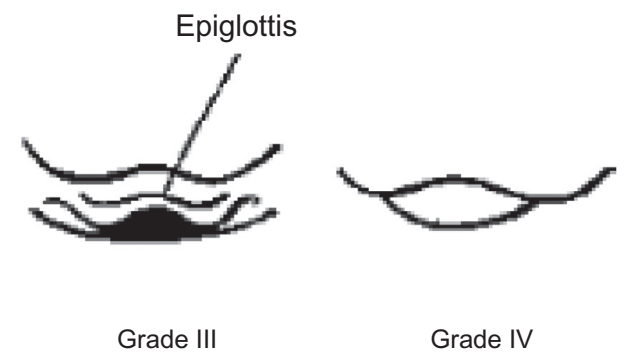

Scale 4

\begin{abstract}
5. Atlanto Occipital (AO) joint extension
\end{abstract}

6. Mandibulo-hyoid distance

7. Inter-incisor distance

\begin{abstract}
Patient faces front with head erect and extends the head maximally; the angle traversed by the occlusal surface of the upper teeth is measured with agoniometer

Measurement from chin to hyoid

Distance between upper and lower incisors
\end{abstract}

Grade I: $>35$

Grade II: $22^{\circ}-34^{\circ}$

Grade III: $12^{\circ}-21^{\circ}$

Grade II: $<12$

At least $4 \mathrm{~cm}$ or 3 finger breadths

Normal: $>4.6 \mathrm{~cm}$

Difficult airway: $<3.8 \mathrm{~cm}$ be tried, where possible. ${ }^{10}$ Trauma also alters the airway structures. The ABC (airway, breathing, and circulation) rule should be followed in this situation. Indications for tracheal intubation include protection of the airway, airway obstruction, positive pressure ventilation, tracheal toilet, and a decreased level of consciousness. Alternatively, orotracheal intubation may be contraindicated or may not be possible in the patient with massive facial, laryngeal, or tracheal trauma. ${ }^{20} \mathrm{~A}$ surgical airway may be necessary instead. ${ }^{1}$ Moreover, obesity (body mass index $\geq 25 \mathrm{~kg} / \mathrm{m}^{2}$ ) alters respiratory pathophysiology and distorts upper airway anatomy. ${ }^{5,21}$ 
Table 2 Congenital and acquired compromising conditions

\section{Congenital:}

Pierre Robin syndrome: micrognathia, macroglossia, cleft soft palate

Treacher-Collins syndrome: auricular and ocular defects, malar and mandibular hypoplasia

Goldenhar syndrome: auricular and ocular defects, malar and mandibular hypolasia

Down syndrome: poorly developed or absent bridge of the nose, macroglossia

Klippel-Feil syndrome: congenital fusion of a variable number of cervical vertebrae, restriction of neck movement

Goiter: compression of trachea, deviation of larynx/trachea

Acquired:

Infections

Supraglottis: laryngeal edema

Croup: laryngeal edema

Abscess (intraoral): distortion of the airway and trismus retropharygeal

Ludwig's angina: distortion of the airway and trismus

\section{Arthritis}

Rheumatoid arthritis: temporomandibular joint ankylosis, cricoarytenoid arthritis, deviation of larynx, restricted mobility of cervical spine

Ankylosing spondylitis: ankylosis of cervical spine, less commonly ankylosis of temporomandibular joints, lack of mobility of cervical spine

\section{Benign tumors}

Cystic hygroma, stenosis or distortion of the lipoma, adenoma, goiter airway, fixation of larynx or adjacent tissues secondary to infiltration or fibrosis from irradiation

Malignant tumor, edema of the airway

Facial injury, hematoma, unstable fraction(s) of the cervical spine injury, maxillae, mandible and cervical laryngeal/tracheal trauma vertebrae

Obesity

Short, thick neck, redundant tissue in the oropharynx, sleep apnea

Acromegaly

Macroglossia, prognathism

Acute burns

Edema of airway

In addition, patient age $>55$ years and lack of teeth has also been associated with DTI. ${ }^{25}$ Finally, acromegaly, tumors, gastric reflux, and pregnancy are included among the factors predisposing a patient to DTI, either through morphologic and anatomic differentiations or pathogenic mechanisms of the underlying condition. ${ }^{26-28}$

Failure to intubate the trachea occurs in one in 2000 patients in the nonobstetric population and one in 300 patients in the obstetric population. ${ }^{22}$ The need for equipment other than a direct laryngoscope may also help define DTI, although devices such as the gum elastic bougie (introducer) may or may not be viewed as part of standard technique. Therefore, the intubation difficulty scale is used, incorporating seven variables to calculate a score. An intubation difficulty scale score of 5 has been used to define DTI and, in a large study, occurred in $8 \%$ of patients. ${ }^{23,24}$

No single airway test can provide a high index of sensitivity and specificity for prediction of difficult airway. Therefore,
Table 3 Difficult airway complications

Laceration of soft tissues
Laryngospasm
Vocal cord paralysis
Dislocation of the arytenoid cartilages or mandible
Perforation of the trachea or the esophagus
Endobronchial or esophageal intubation
Dental damage
Hemorrhage
Aspiration of gastric contents or foreign bodies
Increased intracranial or intraocular pressure
Hypoxemia, hypercarbia
Fracture or dislocation of the cervical spine
Spinal cord damage
Trauma to the eyes

a combination of multiple tests is used. The grading tools and scales most commonly used to assess difficult intubation are presented in Table $1 .{ }^{13}$ They provide accuracy in assessment of preoperative stable patients. Emergency patients are more difficult to assess because of coexisting stress factors, hypoxemia, hypotension, and hypertension, and require intubation under less than optimal conditions. Furthermore, some patients with a difficult airway will remain undetected despite the most careful preoperative airway evaluation. Thus, anesthesiologists must always be prepared with a variety of preformulated and practiced plans for airway management in the event of an unanticipated difficult airway (Table 4).

The most widely used scale is the Mallampati test, which originally categorized patients into three grades according to the ability to visualize the soft palate, fauces, uvula, and anterior and posterior pillars. ${ }^{3}$ In 1987, Samsoon and Young added a fourth grade. ${ }^{22}$ Cormack and Lehane also provided a grading system of four grades according to exposure of the larynx at laryngoscopy. ${ }^{5}$ Their classification also underwent modification by Cook, who subdivided grade II into IIa and IIb, and grade III into IIIa and IIIb. ${ }^{29}$ Wilson developed a scoring system that was based on body weight (<90 kg, 90-110 kg, >110 kg), head and neck movement, jaw movement, mandibular recession, and the presence or absence of protruding ("buck") teeth. ${ }^{30}$ Arne et al ${ }^{31}$ developed a scoring system with seven individual predictive factors, including not only anatomical factors and scales but clinical symptoms and pathologies associated with difficult intubation and history of difficult intubation. Sensitivity ranged from $90 \%$ to $94 \%$, and specificity was $66 \%$ and $96 \%$ for cancer and general surgery, respectively; nevertheless the positive predictive value was low (34\%). In conclusion, the Mallampati test was more accurate than the other predictive factors. The LEMON airway assessment method (Table 5) 
Table 4 Accuracy indexes of prognostic tests for difficult airway

\begin{tabular}{lllll}
\hline Prognostic tests & Types of test characteristics & Sensitivity (\%) & Specialty (\%) & Positive prognostic value (\%) \\
\hline Mallampati test & Category 3 & $44-64$ & $66-89$ & 21 \\
Savva test & $<6 \mathrm{~cm}$ & 7 & 99 & 38 \\
& $<6.5 \mathrm{~cm}$ & $62-64$ & $25-81$ & 16 \\
Petil test & $<12.5 \mathrm{~cm}$ & 82 & 88 & 27 \\
Head extension & $<80^{\circ}$ & 11 & 98 & 30 \\
Mouth opening & $<4 \mathrm{~cm}$ & 26 & 95 & 25 \\
\hline
\end{tabular}

was assessed in two studies, which showed that patients in the difficult intubation group scored higher than those in other groups. $^{32,33}$

Despite the advances in available devices, most airway practitioners tend to resort to the surgical airway approach when facing difficulty in intubation, although the ACLS (advanced cardiac life support) guidelines include a variety of alternatives when tracheal intubation is not achieved. ${ }^{10}$ There are two key parameters for the management of the difficult airway: (1) practitioner experience, and (2) clinical setting. During the last 10 years, many researchers agreed that the flexible fiberoptic endoscope is the single most useful tool when facing a difficult airway. Direct visualization of the upper airway, vocal cords, and tracheal placement ensures correct placement of the endotracheal tube. In some studies, the success rates were as high as $93.9 \%{ }^{11,34}$ The simplest and easiest approach to intubating using a flexible endoscope is that the larynx is in view and the bronchoscope passes through it. Then the operator can rotate the scope and bend its tip when navigating through a difficult airway. This method of intubation allows the practitioner to have a wide variety of choices regarding whether to intubate with the patient awake or asleep, or whether to use an oral or nasal pathway. Most experts agree that awake intubation in an informed adult patient is the safest choice, using local anesthesia and sedation when necessary, whereas children are more difficult to intubate awake. Awake intubation provides for spontaneous respiration and maintenance of upper airway tone. ${ }^{35,36}$

Table 5 The LEMON assessment method

\begin{tabular}{ll}
\hline $\mathrm{L}$ & $\begin{array}{l}\text { Look externally (facial trauma, large incisors, beard } \\
\text { or moustache, large tongue) } \\
\text { E }\end{array}$ \\
& $\begin{array}{l}\text { Evaluate the 3-3-2 rule (incisor distance } 3 \text { finger } \\
\text { breadths, hyoid mental distance } 3 \text { finger breadths, } \\
\text { thyroid-to-mouth distance } 2 \text { finger breadths) }\end{array}$ \\
$\mathrm{M}$ & Mallampati (Mallampati score $\geq 3$ ) \\
$\mathrm{O}$ & Obstruction (trauma, epiglottitis, peritonsilar abscess) \\
$\mathrm{N}$ & Neck mobility \\
\hline
\end{tabular}

\section{Conclusion}

Despite the variety of prediction tests for the difficult airway, none can provide an accurate assessment, so every patient has to be considered as possibly having a difficult airway upon performing an intubation. A combination of scales could be used for early identification of difficult airway intubation with higher sensitivity and specificity results. In most cases the airway has to be maintained for a long period of time with adequate oxygenation and ventilation, and the intubation attempts have to be minimized to avoid injury and complications. Although the conventional laryngoscopic technique remains the standard with a high success rate, every physician who will be required to perform intubation has to be familiar with the process of evaluating a difficult airway and, in the event of the unanticipated difficult airway, be able to use a wide variety of tools and techniques to avoid complications and fatality. The flexible fiberoptic bronchoscope is the gold standard to predict difficult airway and to ensure tube position. Limitations involve purchasing and maintenance costs and skill development.

\section{Acknowledgments}

All authors contributed equally to the preparation of the manuscript.

\section{Disclosure}

Written informed consent was obtained from the patient upon discharge for publication of this case report and all accompanying images. The authors report no conflicts of interest in this work.

\section{References}

1. Benumof JL. Management of the difficult adult airway. With special emphasis on awake tracheal intubation. Anesthesiology. 1991;75(6): 1087-1110.

2. Xie ZZ, Chen JJ, Scamell RW, Gonzalez MA. An interactive multimedia training system for advanced cardiac life support. Comput Methods Programs Biomed. 1999;60(2):117-131.

3. Mallampati SR, Gatt SP, Gugino LD, et al. A clinical sign to predict difficult tracheal intubation: a prospective study. Can Anaesth Soc J. 1985;32(4):429-434.

4. Redick LF. The temporomandibular joint and tracheal intubation. Anesth Analg. 1987;66(7):675-676. 
5. Cormack RS, Lehane J. Difficult tracheal intubation in obstetrics. Anaesthesia. 1984;39(11):1105-1111.

6. Kitamura T, Yamada Y, Du HL, Hanaoka K. Efficiency of a new fiberoptic stylet scope in tracheal intubation. Anesthesiology. 1999;91(6):1628-1632.

7. Cole AF, Mallon JS, Rolbin SH, Ananthanarayan C. Fiberoptic intubation using anesthetized, paralyzed, apneic patients. Results of a resident training program. Anesthesiology. 1996;84(5):1101-1106.

8. Rosenblatt WH, Wagner PJ, Ovassapian A, Kain ZN. Practice patterns in managing the difficult airway by anesthesiologists in the United States. Anesth Analg. 1998;87(1):153-157.

9. Bokhari A, Benham SW, Popat MT. Management of unanticipated difficult intubation: a survey of current practice in the Oxford region. Eur J Anaesthesiol. 2004;21(2):123-127.

10. American Society of Anesthesiologists Task Force on Management of the Difficult Airway. Practice guidelines for management of the difficult airway: an updated report by the American Society of Anesthesiologists Task Force on Management of the Difficult Airway. Anesthesiology. 2003;98(5):1269-1277.

11. Lee A, Fan LT, Gin T, Karmakar MK, Ngan Kee WD. A systematic review (meta-analysis) of the accuracy of the Mallampati tests to predict the difficult airway. Anesth Analg. 2006;102(6):1867-1878.

12. Paix AD, Williamson JA, Runciman WB. Crisis management during anaesthesia: difficult intubation. Qual Saf Health Care. 2005;14(3):e5.

13. Orozco-Diaz E, Alvarez-Rios JJ, Arceo-Diaz JL, Ornelas-Aguirre JM. Predictive factors of difficult airway with known assessment scales. Cir Cir. 2010;78(5):393-399.

14. Salimi A, Farzanegan B, Rastegarpour A, Kolahi AA. Comparison of the upper lip bite test with measurement of thyromental distance for prediction of difficult intubations. Acta Anaesthesiol Taiwan. 2008;46(2):61-65.

15. Shiga $T$, Wajima $Z$, Inoue $T$, Sakamoto A. Predicting difficult intubation in apparently normal patients: a meta-analysis of bedside screening test performance. Anesthesiology. 2005;103(2):429-437.

16. Spittle CS, Beavis SE. Post-intubation tracheal stenosis. Hosp Med. 2001;62(1):54.

17. Spittle N, McCluskey A. Lesson of the week: tracheal stenosis after intubation. BMJ. 2000;321(7267):1000-1002.

18. Bisson A, Bonnette P, el Kadi NB, et al. Tracheal sleeve resection for iatrogenic stenoses (subglottic laryngeal and tracheal). J Thorac Cardiovasc Surg. 1992;104(4):882-887.

19. Brook I, Martin WJ. Bacterial colonization in intubated newborns. Respiration. 1980;40(6):323-328.

20. Chacur FH, Vilella Felipe LM, Fernandes CG, Lazzarini LC. The total face mask is more comfortable than the oronasal mask in noninvasive ventilation but is not associated with improved outcome. Respiration. 2011;82(5):426-430.
21. Brodsky JB, Lemmens HJ, Brock-Utne JG, Vierra M, Saidman LJ. Morbid obesity and tracheal intubation. Anesth Analg. 2002;94(3): 732-736.

22. Samsoon GL, Young JR. Difficult tracheal intubation: a retrospective study. Anaesthesia. 1987;42(5):487-490.

23. Adnet F, Borron SW, Racine SX, et al. The intubation difficulty scale (IDS): proposal and evaluation of a new score characterizing the complexity of endotracheal intubation. Anesthesiology. 1997; 87(6):1290-1297.

24. Adnet F, Racine SX, Borron SW, et al. A survey of tracheal intubation difficulty in the operating room: a prospective observational study. Acta Anaesthesiol Scand. 2001;45(3):327-332.

25. Kheterpal S, Han R, Tremper KK, et al. Incidence and predictors of difficult and impossible mask ventilation. Anesthesiology. 2006; 105(5):885-891.

26. Ramesh BV, Vinod N, Murugesan K. Pharyngeal airway changes following mandibular setback surgery. Indian J Dent Res. 2005; 16(4):147-150.

27. el-Ganzouri AR, McCarthy RJ, Tuman KJ, Tanck EN, Ivankovich AD. Preoperative airway assessment: predictive value of a multivariate risk index. Anesth Analg. 1996;82(6):1197-1204.

28. Schmitt H, Buchfelder M, Radespiel-Troger M, Fahlbusch R. Difficult intubation in acromegalic patients: incidence and predictability. Anesthesiology. 2000;93(1):110-114.

29. Cook TM. A new practical classification of laryngeal view. Anaesthesia. 2000;55(3):274-279.

30. Wilson ME. Predicting difficult intubation. Br J Anaesth. 1993; 71(3):333-334.

31. Arne J, Descoins P, Fusciardi J, et al. Preoperative assessment for difficult intubation in general and ENT surgery: predictive value of a clinical multivariate risk index. Br J Anaesth. 1998;80(2):140-146.

32. Reed MJ, Dunn MJ, McKeown DW. Can an airway assessment score predict difficulty at intubation in the emergency department? Emerg Med J. 2005;22(2):99-102.

33. Soyuncu S, Eken C, Cete Y, Bektas F, Akcimen M. Determination of difficult intubation in the ED. Am J Emerg Med. 2009;27(8):905-910.

34. Heidegger T, Gerig HJ, Ulrich B, Schnider TW. Structure and process quality illustrated by fibreoptic intubation: analysis of 1612 cases. Anaesthesia. 2003;58(8):734-739.

35. Koerner IP, Brambrink AM. Fiberoptic techniques. Best Pract Res Clin Anaesthesiol. 2005;19(4):611-621.

36. Klafta JM. Flexible tracheal tubes facilitate fiberoptic intubation. Anesth Analg. 1994;79(6):1211-1212.
Therapeutics and Clinical Risk Management

\section{Publish your work in this journal}

Therapeutics and Clinical Risk Management is an international, peerreviewed journal of clinical therapeutics and risk management, focusing on concise rapid reporting of clinical studies in all therapeutic areas, outcomes, safety, and programs for the effective, safe, and sustained use of medicines. This journal is indexed on PubMed Central, CAS,

\section{Dovepress}

EMBase, Scopus and the Elsevier Bibliographic databases. The manuscript management system is completely online and includes a very quick and fair peer-review system, which is all easy to use. Visit http://www.dovepress.com/testimonials.php to read real quotes from published authors. 